\title{
Integrating Video Recording and Self-Reflection to Enhance Communication Skills Training for Dental Students
}

\author{
V.Reher ${ }^{1}$, G. Rehbein ${ }^{1}$ and P. Reher ${ }^{1}$ \\ ${ }^{1}$ Griffith University, School of Dentistry and Oral Health, Gold Coast, Australia \\ lncsespringer.com
}

\begin{abstract}
Professional communication skills have a substantial effect on dental patient satisfaction and health outcomes and are one of the core competencies expected of newly graduated dentists in Australia. Acquisition of effective, goaloriented communication skills has been shown to improve the dentist-patient relationship and requires both practicing skills and reflective thinking. The use of technologies such as video-recording to communicate directly and individually with students can be used to enhance students' engagement and communication skills. This paper aims to present the results of the implementation of the video recording of role-plays and self-reflection in the training of communication skills of first-year dental students at Griffith University, Australia. The year 2015 was used as a control, and in 2016 we introduced video recording, and in 2017 selfreflection. The tools used to measure the impact of these teaching instruments were: (1) student evaluation of courses (SEC) data, and (2) results of the final practical exam grades in the Communication Skills for Oral Health Course. The skills assessed and reflected on include: verbal and non-verbal communication, metacommunication, self-confidence, rapport, active listening, and mindfulness. Recordings and facilitator's feedback can be accessed by each student for their self-reflection on their overall performance, communication skills, patient-centered approach and strategies on how to improve their skills. Results of the SEC data show enhancements in engagement (68\% to $83 \%+$ ve answers), assessment ( $66 \%$ to $78 \%+$ ve answers) and feedback ( $81 \%$ to $89 \%+$ ve answers). Results of their average final practical marks increased from $57.82 \%$ (control) to $63.34 \%$ (with video), and finally $79.64 \%$ (with video and self-reflection). These results strongly suggest that the inclusion of the digital recording of role play interactions and self-reflection increases the quality of communication skills training for dental students by enhancing their dentist-patient relationship skills, engagement, confidence, satisfaction with assessment and the quality of the feedback that can be provided.
\end{abstract}

Keywords: Communication skills, Self-Reflection, Video Recording, Dental Education, Blended-learning. 


\section{Introduction}

The patient interview is the health professional's most important and most frequently used tool in assessing a patient's problem, and poor interviewing technique can lead to loss of important and relevant information [1,2]. The quality of relationships between patients and health professionals has a significant impact on patient satisfaction, wellbeing and health outcomes $[3,4]$. A key issue in health professional education is developing basic interpersonal skills before actual patient care, and the importance of practice learning has been increasingly recognized to improve health care [5].

In the field of dentistry, knowledge and technical skills are not the only prerequisites for good practice. An ability to communicate effectively with patients - in particular, to use active listening skills, to gather and impart information effectively, to handle patient emotions sensitively, and to demonstrate empathy, rapport, ethical awareness, and professionalism - is critical. When dentists demonstrate effective communication skills, the benefits noted include: increased patient satisfaction, improved patient adherence to dental recommendations, decreased patient anxiety and negative experiences, lower rates of formal complaints and malpractice claims, and increased patientcentered care [6-11].

Due to the critical role of professional communication skills in promoting these relationships, specific educational content for communication skills training has been developed in a growing number of dental schools [12]. Communication Skills teaching is formally recognized in the United Kingdom by the General Dental Council [13], in the United States, by the American Association of Dental Schools [14], and in Australia, by the Australian Dental Council. Efficient communication skills is one of the six competencies expected of the newly graduated dentist to be eligible for professional registration in Australia [15].

However, despite widespread recognition of the importance of communication skills training in the dental curriculum, the reality of what is practiced is somewhat different, and many programs emphasize theoretical aspects of communication rather than provide opportunities for skills-based practice. In several dental schools, the communication skills teaching often take the form of lectures or passive learning, rather than active skills-based practice using simulated or real patients. The assessment of students is conducted by grading participation in class exercises and assessing knowledge via written or oral tests, rather than directly evaluating student's skills performance $[16,17]$. This method of education is very similar to rote learning, which makes the students forget most of what they have learned soon after evaluations. Clinical skills in dentistry rely on procedural knowledge, which should be easily transferred to real-world problem-solving situations. This requires both an overall understanding of the situation, which fragmental knowledge does not promote, and a contextual learning experience to store knowledge for a long time [5,18].

To offer the best teaching experience and prepare dental students for their professional life, a specific course on communication skills for oral health was introduced in 2013 into the curriculum of the School of Dentistry and Oral Health at Griffith University, Queensland, Australia. The course encompasses a comprehensive approach in- 
cluding important principles recommended for effective communication skills teaching. These include the use of a skills-based approach (as opposed to a didactic approach); clinically relevant scenarios; self-assessment by students; video recording methods; trained simulated patients; monitoring of student performance and delivery of feedback, an integrated teaching team and small groups for optimal student learning By incorporating those elements, it was expected that the program would improve students' interviewing skills, reflective practice and successful life-long learning, all of them cornerstones of patient care [6,16,17, 19-21].

The purpose of this article is to describe how the recent implementation of two specific elements of this comprehensive approach, namely video-recording and self-reflection assessments, have impacted first-years dental science and dental technology students' engagement in the course, their level of satisfaction with the assessments and their communication skills development.

\section{Methods}

This research was a quasi-experimental control-group. Participants were 312 first year oral health students enrolled across three years in the School of Dentistry and Oral Health at Griffith University located in Queensland, Australia. The number of students enrolled was 110 in 2015, 117 in 2016 and 85 in 2017. Ethical clearance to undertake this study was obtained from the Research Ethics and Integrity Team at Griffith University (GU Ref No: 2018/262). All students received an e-mail informing about the research project and asking their permission for the researchers to use their course marks, student experience of courses (SEC) questionnaire and video recording marks in this study. Students were also advised that all content would be anonymous. Participation was voluntary, and students who didn't want to participate had their marks/evaluation removed from the study.

The same lecturer and instructors delivered this course every year (2015-2017). Also, the content, assessment rubrics, markers, and type and difficulty of scenarios in the role-plays were the same throughout the three years. The year 2015 was used as a control group, then in 2016 we introduced the use of video, and in 2017 the use of video and self-reflection. This allows a comparison of the impacts caused by the introduction of these two teaching instruments.

The tools used to measure the impact of these teaching instruments were: (1) SEC data, and (2) Results of the final practical exam grades in the Communication Skills for Oral Health Course. The SEC questionnaire was used to assess students' engagement and satisfaction with the assessment used. The SEC is a University-wide evaluation tool used to gather feedback from students about their courses, the implementation of which is supported by processes that are effective, efficient, comprehensive, systematic and sustainable. The survey contains eight mandatories fixed items (six quantitative, and two qualitative) measuring student's feedback about their courses. All quantitative items were rated on a 5-point Likert scale (ranging from 1 'strongly disagree'; 2 'disagree'; 3 'neutral'; 4 'agree'; to 5 'strongly agree'). The two open-ended questions related to positive aspects of the course and areas for improvement. The data collection 
for the SEC is completed between weeks 11 to 13 each trimester to facilitate the reporting and benchmarking of a course and feedback on teaching data [22].

The second tool used to measure the impact of video and self-reflection techniques was the final practical exam grades in the Communication Skills for Oral Health Course. This exam uses a rubric based on the literature [23], developed to evaluate dentist-patient communication and patient-centered-approach. The skills assessed included verbal and non-verbal communication, metacommunication, self-confidence, assertiveness, rapport, active listening, and mindfulness. Each item was scored on the following 4-point scale: absent or unacceptable (0), minimal (1), developing (2) and competent (3). The rubric was validated by academics of the dental school and has also been validated in previous studies [24,25]. To maintain consistency, all assessments were evaluated by a calibrated teaching team, and moderation processes were in place before and after each assessment.

\section{$3 \quad$ Results}

Of the 312 oral health students who participated in the communication skills course during the years of 2015, 2016 and 2017, 181 (58\%) completed the SEC survey. The number of students enrolled was 110 in 2015, 117 in 2016 and 85 in 2017, with response rates at $62.7 \%, 55.6 \%$, and $55.3 \%$ respectively. All data collected by the survey was statistically examined centrally by the University, using non-parametric and parametric forms of analyses, and reported back to the course coordinator.

The SEC results between 2015 and 2017 can be seen in Figure 1. There was a significant enhancement in students' engagement with the course, their satisfaction with the assessments in place and with the feedback received. Comparing the three years, the percentage of students giving the course a rating of 4 or 5 on the Likert scale ranged from $68.1 \%$ to $83 \%$ positive answers in engagement, $66.7 \%$ to $78.7 \%$ positive answers in assessment satisfaction and $81.2 \%$ to $89.4 \%$ positive answers regarding the feedback received (Fig. 1).

The results of the comparison between the final practical exam marks in 2015 (control), 2016 (introduction of video) and 2017 (introduction of video and self-reflection) are shown in figure 2 . The comparison showed an improvement in their communication skills averaged final marks from $57.82 \%$ in 2015 to $63.34 \%$ in 2016 and reached $79.64 \%$ in 2017. 


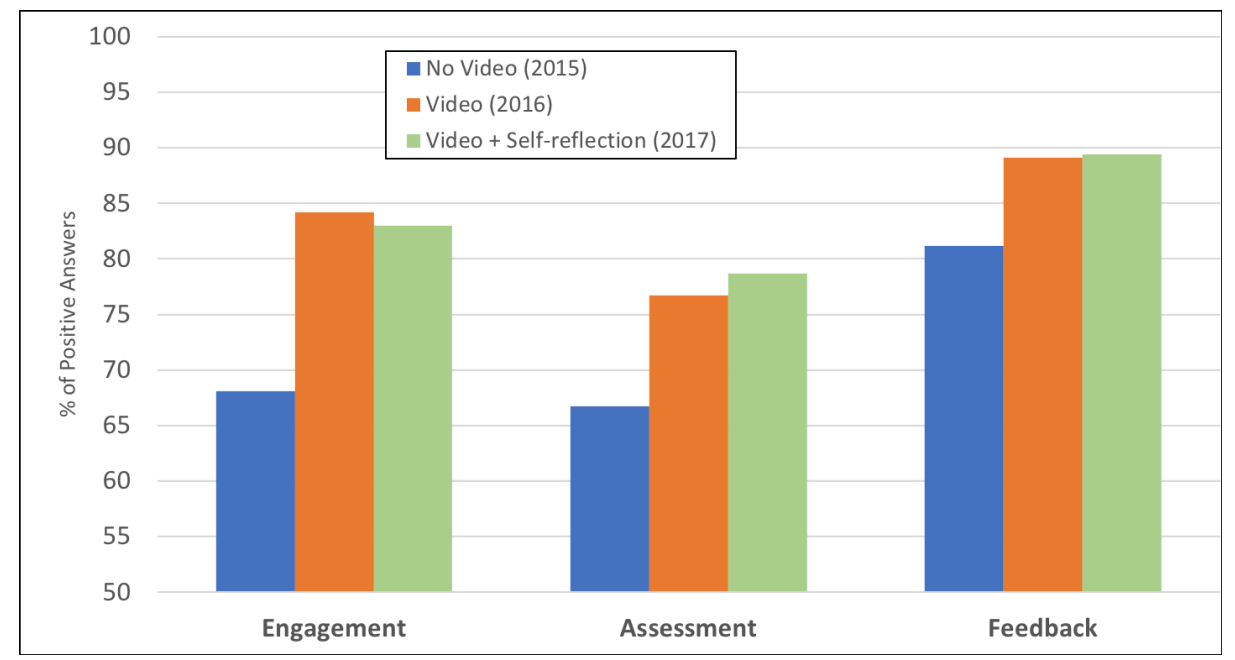

Fig. 1. Comparison of SEC results before and after the introduction of video recording and selfreflection.

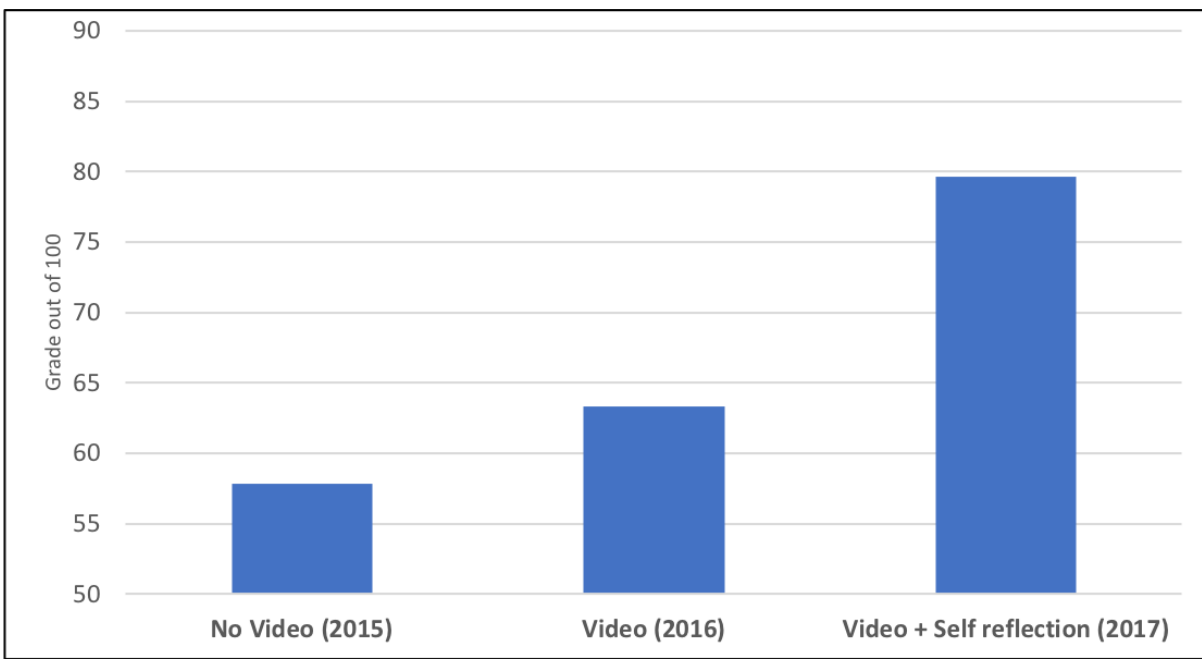

Fig. 2. Students' performance in their averaged final practical exam between the years 20152017: 2015 (control), 2016 (introduction of video), 2017 (introduction of video and self-reflection)

\section{$4 \quad$ Results}

The results of this study reinforce previous reports that video-based self-reflection can improve clinical skills performance, promote self-awareness and self-efficacy, and improve the future professional development of students [26]. Self-evaluation using video enhances knowledge retention, promotes critical thinking, and motivates students to 
become more engaged in their learning. It also allows them to identify their problems and promotes a clearer understanding of the topics to be learned. It indicates a change of attitude in affective dimensions of learning, in that emotions have an important connection to memory and help to store information and trigger its recall [5]. Furthermore, it has been described as a valuable tool for healthcare professionals as they reflect on interpersonal skills [26-28]. The literature also indicates that video is often used in the field of psychology as an effective means of giving feedback and support to students who are learning the subtler aspects of therapeutic communication [29-31]. The results of this study confirm that these instruments are a teaching method that shows a high level of student satisfaction. This was also noted by Epstein et al. (2003), who investigated student satisfaction with video projects on a medical-surgical nursing course. The students reported that using video was a 'fantastic' and 'dramatic' experience and that video-based self-assessment can motivate self-improvement by helping them to identify their strengths and weaknesses, as well as gain insights on the effects of their behaviors [30].

Although video-based self-reflective assessment is thought to be useful in improving the students' understanding of their clinical skills and the problems that they encounter in clinical practice, it is not always appreciated by the students. Sometimes students do not like the ways in which tutors use reflection and self-assessment to help achieve learning goals, or they feel uncomfortable when they observe their behaviors [32]. Further issues raised regarding the use of these methodologies are that they are very time consuming for the teaching staff, and there are concerns about students' readiness and ability to self-assess [28]. While video-based self-assessment does not suit everyone and must be handled with sensitivity when used, it is recommended to lead to greater personal and professional self-awareness of growth and development. This study reinforces the use of these methodologies to offer students insight regarding their practice and to encourage them to become more conscious about the process of learning, especially regarding the development of transferable skills.

\section{Conclusions}

Studies suggest that effective communication skills and patient-centered approach learning involve more than the mere acquisition of information, requiring that learners have more active skills-based practice and reflective assessments. The results of this study suggest that the inclusion of the recording of role-play interactions and self-reflection assessments increases the quality of communication skills training for dental students, by enhancing their dentist-patient relationship skills, engagement, satisfaction with evaluation and the quality of the feedback that can be provided by the facilitators. Further studies are needed to evaluate the efficiency of video-based self-assessment on the performance of other clinical skills and to confirm if these short-term effects can be sustained in the longer term. 


\section{Conflict of Interest}

The authors declare they have no conflict of interests.

\section{References}

1. Roter DL, Hall JA: Physicians' interviewing styles and medical information obtained from patients. J Gen Intern Med 2: 325-329 (1987).

2. Beckman HB, Frankel RM: The effect of physician behavior on the collection of data. Ann Intern Med 101:692-696 (1984).

3. Ayn C, Robinson L, Nason A, Lovas J: Determining Recommendations for Improvement of Communication Skills Training in Dental Education: A Scoping Review. J Dent Educ 81(4): 479-488 DOI 10.21815/JDE.016.003 (2017).

4. Ha JF, Longnecker N: Doctor-patient communication: a review. Ochsner J 10(1):38-43 (2010).

5. Yoo MS, Son YJ, Kim YS, Park JH: Video-based self-assessment: Implementation and evaluation in an undergraduate nursing course. Nurse Educ Today 29: 585-589 (2009).

6. Hannah A, Millichamp CJ, Ayers KMS: A Communication Skills Course for Undergraduate Dental Students. J Dent Educ 68(9): 970-977 (2004).

7. Biro PA, Hewson ND: A survey of patients' attitudes towards their dentists. Aust Dent J 21:388-94 (1976).

8. Corah NL, O'Shea RM, Bissell GD et al.: The dentist-patient relationship: perceived dentist behaviors that reduce patient anxiety and increase satisfaction. J Am Dent Assoc 116:73-6 (1988).

9. Gale EN, Carlsson SG, Eriksson A, Jontell M: Effects of dentists' behavior on patients' attitudes. J Am Dent Assoc 109:444-6 (1984).

10. Mellor AC, Milgrom P: Dentist' attitudes toward frustrating patient visits: relationship to satisfaction and malpractice complaints. J Public Health Dent 56:6-11 (1996).

11. Rouse RA, Hamilton MA: Dentists' technical competence, communication, and personality as predictors of dental patient anxiety. J Behav Med 13(3):307-19 (1990).

12. Haden NK, Hendricson WD, Kassebaum DK, et al.: Curriculum change in dental education, 2003-09. J Dent Educ 74(5):539-57 (2010).

13. General Dental Council: Student professionalism and fitness to practise: Standards for the dental team - Guidance for students. London, England, (2016).

14. American Association of Dental Schools: Curriculum guidelines for behavioral science. J Dent Educ 57(8):648-57 (1993).

15. Australian Dental Council: Australian Dental Council Professional Competencies of the Newly Qualified Dentist. Melbourne, Australia, (2016).

16. Yoshida T, Milgrom P, Coldwell S: How do U.S. and Canadian dental schools teach interpersonal communication skills? J Dent Educ 66:1281-7 (2012).

17. McGoldrick PM, Pine C: A review of teaching of behavioural sciences in the United Kingdom dental undergraduate curriculum. Br Dent J 186:576-80 (1990).

18. Anderson, J: Cognitive Psychology and Its Implication. Freeman and Company, New York (1990).

19. Kupst MJ, Dresser K, Schulman JL, Paul MH: Evaluation of methods to improve communication in the physician-patient relationship. Am J Orthopsychiatry 45:420-9 (1975).

20. Putnam SM, Stiles WB, Jacob MC, James SA: Teaching the medical interview: an intervention study. J Gen Intern Med 3:38-47 (1988). 
21. Silverman J, Kurtz S, Draper J: Defining what to teach and learn: an overview of the communication skills curriculum. In: Silverman J, Kurtz S, Draper J. Skills for communicating with patients. Abingdon, UK: Radcliffe Medical Press 1998:1-16 (1998).

22. Griffith University: Student Experience of Courses (SEC) and Teaching (SET) at: http://policies.griffith.edu.au/pdf/Student Experience of Courses and Teaching.pdf (2014).

23. Curran VR, Casimiro L, Banfield et al: Research for Interprofessional Competency-Based Evaluation (RICE). J Interprof Care 23(3): 297-300 (2008).

24. Curran VR, Hollett A, Casimiro L et al: Development and Validation of the Interprofessional Collaborator Assessment Rubric (ICAR). J Interprof Care 25: 339-344 (2011).

25. Hayward M, Curran VR, Schulz $\mathrm{H}$ et al: Reliability of the Interprofessional Collaborator Assessment Rubric (ICAR) in Multi Source Feedback (MSF) with Post-Graduate Medical Residents. BMC Med Educ, 14:1049 Doi:10.1186/s12909-014-0279-9 (2014).

26. Dearnley CA, Meddings FS: Student self-assessment and its impact on learning - a pilot study. Nurse Educ Today 27(4): 333-340 (2007).

27. Mazor KM, Haley HL, Sullivan K, Quirk ME: The video-based test of communication skills: description, development, and preliminary findings. Teach Learn Med 19(2): 162-167 (2007).

28. Zick A, Granieri M, Makoul G: First-year medical students' assessment of their own communication skills: a video-based, open-ended approach. Patient Educ Couns 68(2): 161-16 (2007)

29. Pinsky LE, Wipf JE: A picture is worth a thousand words: practical use of videotape in teaching. J Gen Intern Med 15(11): 805-810 (2000).

30. Epstein DC, Hovancsesk TM, Dolan, LP et al: Lights! Camera! Action!: Video projects in the classroom. J Nurs Educ 42(12): 558-561 (2003).

31. Travale IL: Computer-assisted instruction for novice nurses in critical care. J Contin Educ Nurs 38(3): 132-138 (2007).

32. Price B: Self-assessment and reflection in nurse education. Nurs Stand 19(29): 33-37 (2005).

Author: Dr Vanessa Reher

Institute: School of Dentistry \& Oral Health, Griffith University

Street: Cnr Olsen Av \& Parklands Dr

City: $\quad$ Southport (Gold Coast), QLD

Country: Australia

Email: v.reher@griffith.edu.au 